\title{
IMPORTÂNCIA DAS PRÁTICAS EDUCATIVAS EM SAÚDE EM UMA ESCOLA DO MUNICÍPIO DE AMANHECE, MG
}

\author{
Lucas de Paiva Dias ${ }^{1}$
}

\begin{abstract}
RESUMO: Este trabalho visa relatar a experiência vivenciada no projeto de extensão intitulado "Programas de Ações Integrais e Integradas de Saúde e Ambiente para Crianças e Adultos de Comunidades Urbanas e Rurais dos Municípios de Uberlândia e Araguari/MG". O trabalho teve vigência entre os meses de agosto e dezembro de 2009 e envolveu crianças de $4^{\mathrm{a}}$ e $5^{\mathrm{a}}$ séries do Ensino Fundamental, totalizando seis salas de aula. Foram ministrados conteúdos relacionados à higiene corporal e oral, lavagem das mãos, crescimento e desenvolvimento, doenças infectocontagiosas, gripe A e sexualidade. A exposição do conteúdo ocorreu por meio de cartazes, teatro e material educativo. A educação em saúde é uma nova abordagem que fornece condições, por meio de atitudes simples, de levar informação e conhecimento sobre hábitos mais saudáveis, bem como mostrar que cada indivíduo possui o controle das condições de sua saúde na busca de melhor qualidade de vida.
\end{abstract}

PALAVRAS-CHAVE: Educação em Saúde. Enfermagem. Qualidade de vida.

The importance of health practices at a school in Amanhece, $M G$

\begin{abstract}
This study aims to describe an experience report about the extension project titled: "Programas de Ações Integrais e Integradas de Saúde e Ambiente para Crianças e Adultos de Comunidades Urbanas e Rurais dos Municípios de Uberlândia e Araguari/MG”. The activities have been registered in August to December 2009, with children of 4th and 5th grades an amount of six rooms. Contents related to general and oral hygiene, hand washing, health growth and development, infectious diseases, influenza A and sexuality through oral presentation, posters, theater and educational material. Health education is a new approach that provides conditions through simple step to bring information and knowledge about a healthier lifestyle emphasizing that each individual has own control of your health conditions seeking better life quality.
\end{abstract}

KEYWORDS: Health education. Nursing. Life Quality.

\section{INTRODUÇÃO}

A experiência aqui relatada advém do projeto de extensão intitulado "Programas de Ações Integrais e Integradas de Saúde e Ambiente para Crianças e Adultos de Comunidades Urbanas e Rurais dos Municípios de Uberlândia e Araguari/MG”, o qual resulta da interação entre os cursos de Educação Física, Enfermagem, Medicina e Odontologia da Universidade Federal de Uberlândia (UFU) com escolas e creches de comunidades dos municípios de Uberlândia e Araguari/MG.

${ }^{1}$ Graduado em Enfermagem pela Universidade Federal de Uberlândia (lucaspaivadias20@hotmail.com). 
Este trabalho foi realizado durante o primeiro semestre de 2008 ao segundo semestre de 2011, com a finalidade de contribuir para a qualidade de vida, detecções e soluções de agravos à saúde e orientações de como adquirir e manter uma boa saúde para os indivíduos envolvidos no projeto, sendo que o foco era atender indivíduos de 5 a 12 anos de idade.

Como citado por Carneiro (2008), educação e saúde são dimensões da vida humana, normalmente separadas, mas que precisam permanecer sempre juntas. Considerando, então, a ampliação do conceito de saúde, para além da ausência de doença, as discussões em torno da questão de como educar indivíduos e grupos para que estes atinjam um nível desejável de saúde têm gerado mudanças nas formas de se educar para a saúde (COSTA, 2005).

O projeto possuía um coordenador geral, pertencente ao curso de Graduação em Odontologia, e dois coordenadores representantes dos cursos já citados. Em relação à participação dos graduandos, houve prioridade para os que cursavam entre o $4^{\circ}$ e $5^{\circ}$ períodos. A seleção foi realizada pelos docentes coordenadores, sendo disponibilizadas 10 vagas para cada curso. Os critérios de escolha foram feitos da seguinte maneira: primeiramente foram aceitos os alunos interessados, caso a quantidade fosse superior a 10 alunos, haveria um processo seletivo simples com questões de múltipla escolha.

As atividades de cada curso foram desenvolvidas em horários diferentes. Em alguns momentos, quando verificado a necessidade, eram realizados trabalhos multiprofissionais, envolvendo os discentes da UFU ligados ao projeto. A cada seis meses, as ações aconteciam em lugares diferentes das comunidades urbanas e rurais dos municípios de Uberlândia e Araguari/MG, selecionados pela necessidade em educação em saúde.

Nossa participação no projeto deu-se no segundo semestre de 2009, momento em que as atividades do concentravam-se em Amanhece (situado a $29 \mathrm{~km}$ da cidade de Araguari-MG), na creche do distrito, envolvendo crianças de 5 a 11 anos. As atividades foram realizadas em seis salas de aula, com duração de 30 minutos cada. Os 10 alunos selecionados foram divididos em dois grupos de 5 alunos cada. As dinâmicas foram realizadas com antecedência, abrindo possibilidade de correção das mesmas pelas coordenadoras do curso.

As ações teórico-práticas aconteciam às quartas-feiras no período matutino, entre os meses de agosto e dezembro de 2009, envolvendo crianças de $5^{\circ}$ e $6^{\circ}$ anos do Ensino Fundamental. Forma ministrados conteúdos (Quadro 1) relacionados à higiene corporal e oral, lavagem das mãos, crescimento e desenvolvimento, doenças infecto-contagiosas, gripe A e sexualidade, por meio de exposição oral, cartazes, teatro e material educativo. 


\section{Descrição das atividades}

Quadro 1 - Descrição das atividades realizadas no Projeto de Extensão "Programas de Ações Integrais e Integradas de Saúde e Ambiente para Crianças e Adultos de Comunidades Urbanas e Rurais dos Municípios de Uberlândia e Araguari/MG".

\begin{tabular}{|c|c|c|c|c|}
\hline Data & Tema & Atividade realizada & \multicolumn{2}{|c|}{$\begin{array}{l}\text { Número } \\
\text { de crianças } \\
\text { presentes }\end{array}$} \\
\hline 12 ago & $\begin{array}{l}\text { Não houve tema } \\
\text { específico }\end{array}$ & $\begin{array}{l}\text { Nesse dia, o objetivo era conhecer o local das } \\
\text { atividades, buscando entender os temas preferidos } \\
\text { e necessários a serem desenvolvidos ao longo } \\
\text { do projeto. Para isso, foi aplicada uma pesquisa, } \\
\text { contendo a opinião dos próprios alunos da } \\
\text { instituição, para definir horário, tema e datas das } \\
\text { atividades }\end{array}$ & $\begin{array}{l}\text { Sala } 1 \\
\text { Sala } 2 \\
\text { Sala } 3 \\
\text { Sala } 4 \\
\text { Sala } 5 \\
\text { Sala } 6\end{array}$ & $\begin{array}{l}22 \\
23 \\
25 \\
25 \\
22 \\
20\end{array}$ \\
\hline 19 ago & $\begin{array}{l}\text { Definição de } \\
\text { Saúde }\end{array}$ & Exposição oral & $\begin{array}{l}\text { Sala } 1 \\
\text { Sala } 2 \\
\text { Sala } 3 \\
\text { Sala } 4 \\
\text { Sala } 5 \\
\text { Sala } 6\end{array}$ & $\begin{array}{l}22 \\
23 \\
25 \\
25 \\
22 \\
20\end{array}$ \\
\hline 26 ago & Dengue & Exposição oral e confecção de painéis & $\begin{array}{l}\text { Sala } 1 \\
\text { Sala } 2 \\
\text { Sala } 3 \\
\text { Sala } 4 \\
\text { Sala } 5 \\
\text { Sala } 6\end{array}$ & $\begin{array}{l}22 \\
23 \\
25 \\
25 \\
22 \\
20\end{array}$ \\
\hline 02 set & $\begin{array}{l}\text { Preservação do } \\
\text { Meio Ambiente }\end{array}$ & Exposição oral, desenhos e confecção de painéis & $\begin{array}{l}\text { Sala } 1 \\
\text { Sala } 2 \\
\text { Sala } 3 \\
\text { Sala } 4 \\
\text { Sala } 5 \\
\text { Sala } 6\end{array}$ & $\begin{array}{l}22 \\
23 \\
25 \\
25 \\
22 \\
20\end{array}$ \\
\hline 09 set & $\begin{array}{l}\text { Lavagem correta } \\
\text { das mãos }\end{array}$ & $\begin{array}{l}\text { Exposição oral, desenhos e confecção de painéis; } \\
\text { demonstração prática, com a utilização de tinta, } \\
\text { água e sabão. }\end{array}$ & $\begin{array}{l}\text { Sala } 1 \\
\text { Sala } 2 \\
\text { Sala } 3 \\
\text { Sala } 4 \\
\text { Sala } 5 \\
\text { Sala } 6\end{array}$ & $\begin{array}{l}22 \\
23 \\
25 \\
25 \\
22 \\
20\end{array}$ \\
\hline 16 set & $\begin{array}{l}\text { Importância da } \\
\text { Higienização } \\
\text { Corporal }\end{array}$ & União e expressão (Dinâmica) & $\begin{array}{l}\text { Sala } 1 \\
\text { Sala } 2 \\
\text { Sala } 3 \\
\text { Sala } 4 \\
\text { Sala } 5 \\
\text { Sala } 6\end{array}$ & $\begin{array}{l}22 \\
23 \\
25 \\
25 \\
22 \\
20\end{array}$ \\
\hline
\end{tabular}




\begin{tabular}{|c|c|c|c|c|}
\hline 23 set & $\begin{array}{l}\text { Importância da } \\
\text { Alimentação }\end{array}$ & Confecção de cartazes pelos alunos & $\begin{array}{l}\text { Sala } 1 \\
\text { Sala } 2 \\
\text { Sala } 3 \\
\text { Sala } 4 \\
\text { Sala } 5 \\
\text { Sala } 6\end{array}$ & $\begin{array}{l}22 \\
23 \\
25 \\
25 \\
22 \\
20\end{array}$ \\
\hline 30 set & $\begin{array}{l}\text { Pediculose e } \\
\text { Escabiose }\end{array}$ & Exposição oral & $\begin{array}{l}\text { Sala } 1 \\
\text { Sala } 2 \\
\text { Sala } 3 \\
\text { Sala } 4 \\
\text { Sala } 5 \\
\text { Sala } 6\end{array}$ & $\begin{array}{l}22 \\
23 \\
25 \\
25 \\
22 \\
20\end{array}$ \\
\hline 07 out & Envelhecimento & Exposição oral & $\begin{array}{l}\text { Sala } 1 \\
\text { Sala } 2 \\
\text { Sala } 3 \\
\text { Sala } 4 \\
\text { Sala } 5 \\
\text { Sala } 6\end{array}$ & $\begin{array}{l}22 \\
23 \\
25 \\
25 \\
22 \\
20\end{array}$ \\
\hline 14 out & $\begin{array}{l}\text { Educação no } \\
\text { Trânsito }\end{array}$ & Apresentação das regras de trânsito & $\begin{array}{l}\text { Sala } 1 \\
\text { Sala } 2 \\
\text { Sala } 3 \\
\text { Sala } 4 \\
\text { Sala } 5 \\
\text { Sala } 6\end{array}$ & $\begin{array}{l}22 \\
23 \\
25 \\
25 \\
22 \\
20\end{array}$ \\
\hline 21 out & $\begin{array}{l}\text { Cuidados } \\
\text { com Animais } \\
\text { Peçonhentos }\end{array}$ & Exposição oral & $\begin{array}{l}\text { Sala } 1 \\
\text { Sala } 2 \\
\text { Sala } 3 \\
\text { Sala } 4 \\
\text { Sala } 5 \\
\text { Sala } 6\end{array}$ & $\begin{array}{l}22 \\
23 \\
25 \\
25 \\
22 \\
20\end{array}$ \\
\hline 28 out & $\begin{array}{l}\text { Doenças } \\
\text { Infectocontagiosas }\end{array}$ & Exposição oral, desenhos e confecção de painéis & $\begin{array}{l}\text { Sala } 1 \\
\text { Sala } 2 \\
\text { Sala } 3 \\
\text { Sala } 4 \\
\text { Sala } 5 \\
\text { Sala } 6\end{array}$ & $\begin{array}{l}22 \\
23 \\
25 \\
25 \\
22 \\
20\end{array}$ \\
\hline 11 nov & $\begin{array}{l}\text { Crescimento e } \\
\text { desenvolvimento }\end{array}$ & Exposição oral & $\begin{array}{l}\text { Sala } 1 \\
\text { Sala } 2 \\
\text { Sala } 3 \\
\text { Sala } 4 \\
\text { Sala } 5 \\
\text { Sala } 6\end{array}$ & $\begin{array}{l}22 \\
23 \\
25 \\
25 \\
22 \\
20\end{array}$ \\
\hline
\end{tabular}




\begin{tabular}{|c|c|c|c|c|}
\hline \multirow[t]{6}{*}{18 nov } & Mudanças & Exposição oral e utilização de vídeos educativos & Sala 1 & 22 \\
\hline & Corporais & & Sala 2 & 23 \\
\hline & & & Sala 3 & 25 \\
\hline & & & Sala 4 & 25 \\
\hline & & & Sala 5 & 22 \\
\hline & & & Sala 6 & 20 \\
\hline \multirow[t]{6}{*}{25 nov } & Conceitos sobre & Exposição oral e utilização de vídeos educativos & Sala 1 & 22 \\
\hline & Sexualidade & & Sala 2 & 23 \\
\hline & & & Sala 3 & 25 \\
\hline & & & Sala 4 & 25 \\
\hline & & & Sala 5 & 22 \\
\hline & & & Sala 6 & 20 \\
\hline \multirow[t]{6}{*}{$02 \mathrm{dez}$} & Gripe A & Exposição oral e utilização de vídeos educativos & Sala 1 & 22 \\
\hline & & & Sala 2 & 23 \\
\hline & & & Sala 3 & 25 \\
\hline & & & Sala 4 & 25 \\
\hline & & & Sala 5 & 22 \\
\hline & & & Sala 6 & 20 \\
\hline \multirow[t]{6}{*}{$9 \mathrm{dez}$} & Diferenças entre & Exposição oral e utilização de vídeos educativos & Sala 1 & 22 \\
\hline & Gripe Comum e & & Sala 2 & 23 \\
\hline & Gripe A & & Sala 3 & 25 \\
\hline & & & Sala 4 & 25 \\
\hline & & & Sala 5 & 22 \\
\hline & & & Sala 6 & 20 \\
\hline
\end{tabular}

Fonte: Elaborado pelo autor.

\section{Avaliação das atividades}

Existem várias maneiras de se executar o trabalho de Enfermagem na sociedade atual. Isso acontece devido ao fato de a educação em saúde vir se destacando como sendo o mais importante método de promoção da saúde (SOUZA, 2005). Então, conhecer primeiramente o local das atividades foi muito importante, uma vez que tornou possível a criação de um vínculo com os funcionários da instituição, ligação esta que também auxiliou a ganhar a confiança dos alunos.

A primeira atividade (higienização corporal) despertou grande participação, assim como a lavagem correta das mãos. Na abordagem da gripe A, a interação não foi tão significativa, talvez pelo fato de o método utilizado ter sido o teatro. Já na abordagem de mudanças corporais e sexualidade, as dúvidas foram muitas, assim como o receio de se fazer questionamentos.

As dinâmicas sobre envelhecimento e sobre educação no trânsito, por sua vez, foram as que menos chamaram atenção dos alunos, embora sejam fundamentais, em especial a última. Isso porque, no transcorrer desta atividade, muitos alunos citaram acidentes com veículos automotores envolvendo 
familiares e conhecidos, fato que evidencia a necessidade dos conhecimentos básicos acerca do assunto.

Portanto, a educação em saúde é uma abordagem que evidencia que cada indivíduo possui o controle das condições de sua própria saúde na busca de melhor qualidade de vida e pode ser abordada por meio de atitudes simples como a de levar informação, conhecimentos e hábitos de vida mais saudáveis aos participantes do projeto em questão.

No início das primeiras atividades, sobre o conceito de saúde, $45 \%$ das crianças presentes definiram a educação em saúde como sendo a transmissão de conhecimentos de alguém que os detém para outra que não os possui, ótica substituída pela concepção de que, no ato de compartilhar os saberes, todos os agentes envolvidos estão sujeitos ao aprendizado. Sendo assim, é muito importante que os envolvidos tenham participação ativa na busca de melhores condições de saúde (OLIVEIRA; OLIVEIRA, 2009).

\section{CONSIDERAÇÕES FINAIS}

A Enfermagem é uma ciência cujo objetivo é o cuidado do ser humano, seja individualmente ou em comunidade, uma vez que promover saúde é importante para a qualidade de vida das pessoas.

A busca de uma maior participação dos indivíduos na melhoria das condições de vida e saúde, unidas ao trabalho em grupo nas comunidades constituem, então, importantes ferramentas para a conscientização crítica dos indivíduos a respeito do seu meio social.

Sendo assim, pelo trabalho, evidencia-se a relevância de práticas educativas em saúde nas escolas, local privilegiado para iniciar a conscientização pela busca de melhores condições de saúde por meio das descobertas e reflexões dos sujeitos sobre a realidade.

O projeto propiciou aos graduandos outra perspectiva mediante as práticas educativas que desempenhadas durante o decorrer do curso, questão importante no aprendizado e no crescimento pessoal e profissional.

Enfim, ao longo do projeto, percebemos algumas modificações importantes quanto à postura das crianças em relação à saúde, como, por exemplo, ir para a escola trajando roupas limpas e com as mãos higienizadas, uma vez que, conforme relatos da diretora e dos professores da instituição, muitas delas sequer tomavam banho. Os índices de piolho e mau cheiro no recinto da sala de aula, em virtude da bromidrose (popularmente conhecido como chulé), diminuíram consideravelmente, evidenciando os resultados positivos de nosso trabalho. 


\section{REFERÊNCIAS}

CARNEIRO, N.P. Educação e Saúde. Web Artigos, 26 mar. 2008. Disponível em: < http://www. webartigos.com/articles/5020/1/educacao-e-saude/pagina1.html $>$. Acesso em: 29 jun.2011.

COSTA, H. A Educação que produz saúde. Ministério da Saúde. 2005. Disponível em: $<$ http://bvsms.saude.gov.br/bvs/publicacoes/a_educacao_que_produz_saude.pdf $>$. Acesso em: 29 jun.2011.

OLIVEIRA, J. M. A.; OLIVEIRA, M. C. M. Educação em saúde: do Campanhismo ao Saúde da Família. Disponível em: <http://www.sbhe.org.br/novo/congressos/cbhe4/individuais- coautorais/ eixo05/ Joseane\%20 Maria\%20Andrade\%20 Mouzinho\%20de\%20Oliveira\%20e\%20Maria\%20 Cecilia\%20M.pdf> Acesso em: 30 jun. 2011.

SOUZA, A. C. et al. A educação em saúde com grupos na comunidade: uma estratégia facilitadora da promoção da saúde. Rev. Gaúcha Enferm., Porto Alegre v. 26, n. 2, p.147-153, ago. 2005.

Submetido em 12 de março de 2012.

Aprovado em 8 de julho de 2012. 